\title{
Migração com rosto feminino: múltiplas vulnerabilidades, trabalho doméstico e desafios de políticas e direitos
}

\author{
Jaqueline Bertoldo ${ }^{1}$ \\ https://orcid.org/0000-0002-3090-3417 \\ ${ }^{1}$ Universidade Federal de Santa Maria, Departamento de Direito, Programa de Pós-Graduação em Direito, Santa Maria, RS, Brasil \\ (UFSM)
}

\begin{abstract}
Migração com rosto feminino: múltiplas vulnerabilidades, trabalho doméstico e desafios de políticas e direitos

Resumo: Sabe-se que atualmente a migração internacional é majoritariamente feminina, como resultado da feminização da pobreza e das grandes desigualdades econômicas ao redor do mundo. Cada vez mais se constata a presença de mulheres que se inserem em fluxos migratórios e acabam inseridas em nichos de trabalho historicamente destinados às mulheres, como no serviço doméstico. Assim, o questionamento que direciona a pesquisa é compreender que elementos caracterizam as múltiplas vulnerabilidades das migrantes domésticas no país e consequentemente os desafios para uma política migratória brasileira atenta a esses processos de exploração e produção de desigualdades. O objetivo do presente trabalho é entender a realidade dos fluxos migratórios de domésticas para o país, refletindo desde as desigualdades entre gênero, classe social e raça, e assim perceber os desafios da atual política migratória brasileira com relação à exploração e desigualdades vivenciadas. O método de abordagem a ser utilizado na pesquisa será o dialético, tendo em vista a análise do objeto a partir das contradições internas da realidade das mulheres migrantes para o trabalho doméstico. A partir dos estudos realizados, identificou-se como essas mulheres ainda enfrentam os grandes dilemas da migração, ou seja, o controle por parte do Estado, a segregação laboral, as relações trabalhistas abusivas e as lógicas de servidão, a discriminação étnico-racial, o isolamento e o preconceito, trazendo uma série de desafios para avanço da Política Migratória Brasileira e promoção dos direitos humanos das mulheres migrantes. Palavras-chave: Migração feminina. Trabalho doméstico. Política migratória brasileira.
\end{abstract}

Female migration: multiple vulnerabilities, domestic work and challenges in policies and rights Abstract: It is known that international migration is nowadays predominantly female, as a result of the feminization of poverty and the great economic inequalities around the world. Increasingly, women who are included in migratory flows, end up inserted in niches of work historically destined for women, such as domestic service. Thus, this research seeks to understand what elements characterize the multiple vulnerabilities of domestic migrants in Brazil and consequently the challenges for a national migration policy that considers these processes of exploitation and production of inequalities. The aim is to understand the reality of the migratory flows to Brazil specifically of women working in domestic services, which reflects inequalities between gender, social class and race. Therefore, the study contributes to understand the challenges of the current national migratory policy in relation to the exploitation and inequalities experienced. The method of dialectic approach was used in the research, in view of the analysis of the object from the internal contradictions of the reality of women migrating doing domestic work. It was possible to identify how these women still face the great dilemmas of migration, that is, the control by the State, labor segregation, abusive labor relations and the logics of servitude, ethnic-racial discrimination, isolation and prejudice, bringing a series of challenges to the advancement of the Brazilian Migration Policy and the promotion of human rights for migrant women.

Keywords: Female migration. Domestic work. Brazilian migration policy.

Recebido em 15.10.2017. Aprovado em 08.02.2018. Revisado em 15.03.2018.

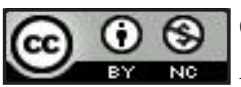

C O(s) Autor(es). 2018 Acesso Aberto Esta obra está licenciada sob os termos da Licença Creative Commons Atribuição-NãoComercial 4.0 Internacional (https://creativecommons.org/licenses/by-nc/4.0/deed.pt_BR), que permite copiar, distribuir e reproduzir em qualquer meio, bem como adaptar, transformar e criar a partir deste material, desde que para fins não comerciais e que você forneça o devido crédito aos autores e a fonte, insira um link para a Licença Creative Commons e indique se mudanças foram feitas. 


\title{
Introdução
}

\author{
Para comprender las formas concretas en que resultan afectadas las mujeres, \\ es menester examinar la migración de la mujer desde la perspectiva de la desigualdad \\ entre los géneros, las funciones tradicionales de la mujer, el desequilibrio del mercado laboral \\ desde el punto de vista del género, la prevalencia generalizada de la violencia \\ por motivo de género y la feminización de la pobreza y la migración laboral a nivel mundial. \\ Derechos Humanos de las trabajadoras migrantes. \\ (COMITÊ PARA ELIMINAÇÃO DA DISCRIMINAÇÃO CONTRA AS MULHERES, 2005, p. 4).
}

Atualmente, sabe-se que mais da metade da população migrante é feminina e que ao mesmo tempo, em níveis mundiais, a pobreza também tem rosto feminino. Assim, cada vez mais se constata a presença de mulheres que se inserem em fluxos migratórios para poder trabalhar, dar sustento à família e aos filhos, garantir acesso à educação, fugir de relações violentas, em função de arranjos familiares ou pelas redes de migração.

Do outro extremo, frequentes também os discursos que propagam o avanço de ideias neoliberais, da livre circulação de capitais ao redor do mundo e da modernização e evolução das relações trabalhistas, além de ampla difusão acerca da liberdade feminina no mundo contemporâneo, sua emancipação e saída do lar para integrar o mercado de trabalho. A partir dessas contradições, o questionamento que direciona a pesquisa é compreender que elementos caracterizam as múltiplas vulnerabilidades das mulheres migrantes domésticas no país e consequentemente os desafios para uma política migratória brasileira atenta a esses processos de exploração e produção de desigualdades.

Assim, o objetivo do presente trabalho é entender a realidade dos fluxos migratórios de domésticas para o País, refletindo desde as desigualdades entre gênero, classe social e raça, e assim perceber os desafios da atual política migratória brasileira com relação à exploração e desigualdades vivenciadas. A importância e originalidade da presente pesquisa se dão na medida em que o trabalho analisa e sistematiza as diversas faces da migração feminina no Brasil, identificando os elementos que colocam essas mulheres como sujeitos vulneráveis, bem como avança em termos científicos apontando os desafios que essa realidade apresenta ao campo jurídico, em especial em um momento de mudanças legislativas sobre o tema. Destaca-se também que o tema já tem sido objeto de amplo debate no nível da Alta Política por meio das Organização das Nações Unidas (ONU) e outros organismos internacionais, sendo fundamental que a discussão também seja introduzida no âmbito interno. Sendo assim, objetiva-se que a difusão dos conhecimentos científicos aqui apresentados possa contribuir no avanço das políticas públicas no Brasil, indo ao encontro das recomendações internacionais de proteção dos direitos das mulheres migrantes.

O método de abordagem a ser utilizado na pesquisa será o dialético, tendo em vista a análise do objeto a partir das contradições internas do fluxo de mulheres migrantes para o trabalho doméstico. Como método de procedimento, utilizar-se-á o histórico, na medida em que se buscará compreender como o trabalho feminino foi sendo explorado e desvalorizado ao longo da história, para, em um segundo momento compreender como essa construção histórica gera desigualdades e contradições a partir do fluxo de mulheres para o trabalho doméstico no País. A técnica de pesquisa será a bibliográfica, por meio de ampla revisão de literatura sobre a temática.

Assim, inicialmente busca-se fazer uma revisão teórica acerca da inserção das mulheres nos fluxos migratórios internacionais, compreendendo como o trabalho feminino tem sido explorado por meio das redes migratórias de trabalho doméstico. Em um segundo momento, pretende-se identificar quais as situações de vulnerabilidade vivenciadas pelas migrantes domésticas no país, percebendo como o elemento da nacionalidade constrói os elementos de exploração desse grupo social. Por fim, como forma de síntese, objetiva-se compreender quais os desafios da atual política migratória brasileira para promoção dos direitos das trabalhadoras domésticas migrantes e superação dos processos de exploração e desigualdades identificados.

\section{As mulheres no cenário migratório}

O aumento do número de mulheres nos fluxos migratórios internacionais e consequentemente sua maior visibilidade, principalmente através dos estudos de gênero, puderam retirar esses sujeitos do anonimato e redefini-los como atores centrais nos movimentos migratórios (MAGLIANO, 2007). Nesse sentido é que Maria Jose Magliano (2007) explica que os processos de mobilidade humana são marcados pelas relações de gênero, ou seja, as relações sociais de sexo são elementos estruturantes do fenômeno migratório, atuando simultaneamente com outros aspectos como de classe social e etnia: "A subordinação em termos de gênero, classe social e etnia constituem o marco referencial para qualquer análise dos processos que produ- 
zem e reproduzem formas de marginalização e exclusão das mulheres migrantes". (MAGLIANO, 2007, p. 2, tradução nossa).

O gênero como construção social que constitui as expectativas e expressões do masculino e do feminino de uma sociedade influencia o modo como se reproduzem a subordinação e a desigualdade, afetando especialmente as mulheres migrantes, pela sua condição de mulheres e de migrantes, e também pelo pertencimento de classe e sua origem étnica. (MAGLIANO, 2007, p. 4, tradução nossa).

Assim, o aumento das migrações femininas internacionais traz à tona novas questões para serem pensadas e discutidas no cenário político, tendo em vista a influência das relações sociais de sexo e também de raça no processo de mobilidade de mulheres. Todas essas temáticas se relacionam e tentam explicar como se dá a inserção de tantas mulheres migrantes no mercado assistencial, o que se passa a expor agora.

A desigualdade crescente entre os países, as mudanças demográficas, além de uma série de conflitos internos nos países, têm interagido constantemente para produzir um crescimento sem precedentes em termos de mobilidade humana. Dados do Departamento de Assuntos Econômicos e Sociais das Nações Unidas (ORGANIZAÇÃO DAS NAÇÕES UNIDAS, 2015) revelam que o número de migrantes internacionais já atingiu 244 milhões no ano de 2015, um aumento de $41 \%$ desde o ano 2000. De acordo com recentes estimativas da Organização Internacional do Trabalho (OIT) (2015) quase 150,3 milhões desses estão no mercado de trabalho e quase metade são mulheres. Em nível global, existem 67,1 milhões de trabalhadores domésticos, dos quais 11,5 milhões são migrantes internacionais. Sendo assim, os migrantes representam 17,2\% de todos os trabalhadores domésticos do mundo. A própria OIT, no entanto, afirma que esses números podem estar subestimados tendo em vista a ocupação no setor informal ou de imigrantes indocumentados.

Nesse sentido, os estudos migratórios passaram a constatar diversas situações desse fluxo migratório de mulheres que deixam seus países, buscando alternativas de renda para si e suas famílias inserindo-se no mercado da assistência, em profissões como as de cuidadoras, domésticas e babás. Com o aprofundamento nos estudos, passou-se a conceituar esse fluxo migratório como cadeias globais de cuidado (global care chain), cujo termo foi inicialmente apresentado por Russell Hochschild, que partiu do estudo de Parreñas sobre a migração de domésticas em Los Angeles e Roma (YEATES, 2004).

A pesquisa de Hochschild (apud YEATES, 2004) trata especificamente sobre as transferências transnacionais da mão de obra materna, tendo identificado uma cadeia em que uma filha mais velha de uma família pobre cuida de seus irmãos enquanto sua mãe trabalha como babá cuidando dos fillhos de outra babá que, por sua vez, cuida dos filhos de uma mulher rica em outro país. Vários são os processos envolvidos nesse conceito, principalmente a ideia de terceirização dos serviços de cuidado à família. Essa terceirização, que pode se dar tanto em escala nacional, como é o caso da migração rural-urbana, hoje ocorre cada vez mais em nível internacional, transfronteiriça ou transregional, implicando no recrutamento de mão de obra através das redes informais de migração.

A OIT apresenta uma série de fatores e interações que explicam a demanda pelo trabalho doméstico de migrantes: a) a dificuldade cada vez maior que as famílias enfrentam em lidar com o trabalho remunerado e as responsabilidades familiares; b) o envelhecimento da população e crescimento da expectativa de vida, juntamente com as menores taxas de fertilidade que têm colocado em tensão os tradicionais modelos de cuidado; c) o aumento do custo de vida, juntamente com a segmentação do mercado de trabalho, a violência doméstica e familiar e o não acesso à educação, ou seja, situações para as quais não resta outra opção para essas mulheres a não ser migrar (TAYAH, 2016).

Evidencia-se como resultado desses fluxos migratórios uma das faces perversas da globalização: um novo tipo de economia, parcialmente desterritorializada, que atravessa fronteiras conectando múltiplos pontos do globo, numa espécie de rede submersa, informal e ilegal, originando desregulamentação e precarização das relações de trabalho (LISBOA, 2007, p. 807, grifo nosso).

Toda essa dinâmica revela a maneira perversa de como a mulher tem sido inserida na articulação da economia global, estando intimamente associada aos fenômenos da feminização da pobreza e por outro lado, a forma utilitária como o mercado se apropria dessa mão de obra. De um lado, agências que lucram bilhões a partir do comércio do trabalho feminino, tanto em redes de prostituição como no tráfico de migrantes para trabalhos ligados ao ambiente doméstico. Por outro, a cara da pobreza mundial é feminina, sendo que os dados da ONU revelaram que $70 \%$ dos pobres são mulheres (LISBOA, 2007).

Não há como não associar a crescente desigualdade do mundo neoliberal com os fluxos de mulheres domésticas para o primeiro mundo, gerando uma nova estrutura que acaba por oprimir essas migrantes, contri- 
buindo para vulnerabilizá-las ainda mais. Os paradoxos e contradições são evidentes: enquanto o capitalismo e as novas dinâmicas da economia global incentivam esses fluxos, cuida também para que essas pessoas possam ser consideradas sujeitos políticos dentro das nações que as acolhem, com acesso aos direitos mínimos de todo trabalhador e trabalhadora?

A divisão sexual do trabalho, na qual o trabalho doméstico acabou por ser delegado exclusivamente às mulheres e, por isso, inferiorizado, acabou também por transformar-se em um problema privado (LISBOA, 2007). Tudo isso acaba por invisibilizar totalmente o problema e juntamente com a ausência do papel do Estado, agrava drasticamente a situação dessas mulheres. Quando migram de forma irregular, são consideradas ilegais e assim não têm acesso a qualquer direito; quando entram regularmente no país para trabalhar ainda assim são invisibilizadas por sua condição de mulher e migrante, tendo que lutar, com os poucos meios que têm, para sobreviver.

Conclui-se que tanto os fatores raciais, bem como os baixos custos e a capacidade de controle desse trabalho são os principais fatores que explicam a procura dessa mão de obra migrante. O comércio internacional de mão de obra doméstica se insere no contexto de feminização das migrações e é, em parte, respostas do desenvolvimento desigual ao redor do mundo. O pensamento de Hirata (apud VILLEN, 2013, p. 6) explica que o sistema de mundialização dos serviços de cuidado é organizado pela utilização do trabalho das mulheres, imigrantes e de classes subalternas sendo que os beneficiários dessa ordem são: "1) o capital globalizado que maximiza seus lucros; 2) a classe dos homens; 3 ) as mulheres das classes sociais mais favorecidas".

Diante de um panorama geral acerca das transformações das relações de trabalho com o desenvolvimento de uma economia globalizada, busca-se a partir de agora compreender de maneira mais aprofundada as realidades em que estão inseridas as mulheres migrantes trabalhadoras no setor doméstico.

\section{As múltiplas vulnerabilidades da mulher trabalhadora migrante: as barreiras da nacionalidade}

A partir da problemática anteriormente apresentada e do aumento do fluxo de mulheres migrantes domésticas ao redor do mundo, a presente seção tem como objetivo compreender as múltiplas vulnerabilidades em que se encontram essas mulheres ao aderirem ao projeto migratório.

Compreender a realidade migratória mundial passa necessariamente pelo estudo da relação entre o sujeito migrante e o modelo do Estado-Nação. A mulher migrante, além da situação de vulnerabilidade sofrida na condição de mulher, encontra também uma barreira na vulnerabilidade do sujeito imigrante, confinado a uma condição de não nacional pelo modelo político-jurídico do Estado Nacional e, por isso, um não sujeito. Reduzido à "vida nua" em função de sua condição de estrangeiro, esse sujeito é remetido a um espaço de privação, caracterizado pela ausência de voz e ação (REDIN, 2013, p. 22).

Todo esse cenário que caracteriza o espaço-tempo das migrações contemporâneas coloca o(a) migrante em situação de múltiplas vulnerabilidades, sendo que a privação dos seus direitos humanos fundamentais se dá na medida em que sua opinião não é significativa e sua ação não é eficaz perante o espaço público. Através dessas premissas nota-se como a realidade do(a) migrante os coloca em um patamar distante dos nacionais, sendo que sua presença nunca é plena no espaço do Estado, tanto política, jurídica e simbolicamente.

Daqui em diante, a partir da realidade vivida pelas migrantes domésticas no Brasil, pretende-se analisar as contradições do modelo Estatal que desiguala as mulheres migrantes das mulheres autóctones, para excluílas através do critério da nacionalidade, e ao mesmo tempo ignora suas diferenças e experiências como categoria e grupo vulnerável. $\mathrm{O}$ estudo é realizado a partir de diversos trabalhos de pesquisadoras junto às realidades de migrantes aqui no Brasil - como a Dra. Délia Dutra - e em alguns casos em outros países da América Latina, como Chile e Argentina, pela proximidade entre as realidades. Propõem-se assim, perceber as contradições existentes na dinâmica do espaço-tempo da migração internacional de mulheres, tratadas como desiguais enquanto objetos de controle do Estado e ao mesmo tempo, desconsideradas em suas especificidades enquanto categoria vulnerável.

Lussi e Marinuci (2007) explicam que a vulnerabilidade não é uma característica inerente à pessoa do imigrante, mas sim à situação que eles e elas se encontram em razão do processo migratório. São as fragilidades e complexidades da situação "psicofísica, jurídica e socioeconômica" daqueles que estão em mobilidade que determinam essa condição de vulnerabilidade, estando sujeitos a diversas formas de riscos sociais (LUSSI, 2009, p. 2).

Todo processo de mobilidade de mulheres de determinadas origens sociais e étnicas revela uma série de elementos que caracterizam sua condição como vulnerável diante de demais grupos sociais, sendo nesse caso marcado pelo limite da nacionalidade. A migração feminina não por acaso é associada à feminização da pobreza, tendo em vista que o fato de uma mulher estar exercendo o trabalho doméstico em um país estrangei- 
ro pressupõe antes uma série de elementos que a fez deixar seu país de origem e ingressar em um projeto migratório arriscado, sendo normalmente uma das poucas opções que se apresentam para tantas mulheres.

Desde o desemprego e a falta de oportunidades, a pobreza, violências familiares, necessidade de sustentar a família, melhor condições de educação para os filhos, existência de redes sociais e familiares, dentre outras situações estão nas motivações que levam as mulheres a migrar, buscando dar respostas às necessidades básicas do cotidiano. O aumento das famílias monoparentais e a necessidade do sustento da família e filhos colocam em questão a situação dessas migrantes como agentes fundamentais no envio de remessas de dinheiro para o exterior, colocando-as sempre entre dois mundos, aquele onde está agora e aquele onde estão os que ficaram.

A pesquisa que Dutra (2013a, p. 99) realizou com um público de 20 imigrantes paraguaias no Brasil revelou, por exemplo, que somente uma das migrantes entrevistadas estava morando com um dos seus filhos (outros haviam ficado no Paraguai); cinco mulheres responderam que haviam deixado seus filhos no país de origem e as demais relataram sobre outros parentes, como irmãos e pais, "porém nenhuma menciona ter deixado marido". Ou seja, a migração feminina é marcada por uma série de arranjos em torno das relações afetivas, da necessidade de sobrevivência, de cuidado e subsistência de toda a família, de melhores oportunidades para os filhos.

Ainda dentro desse tópico, a tese de Doutorado de Délia Dutra, que apresenta uma pesquisa de campo com 10 peruanas trabalhadoras domésticas residentes na cidade de Brasília, traz a realidade das migrantes que deixaram seus filhos no Peru (4 delas) e que relatam guardar todo o dinheiro recebido para enviar aos filhos ficando “só com um 'trocado' para despesas pessoais de farmácia e transporte” (DUTRA, 2012, p. 88). Segundo a pesquisa, uma delas inclusive relatou que o empregador tirava vantagem disso, pois guardava todo o dinheiro referente ao salário, seis ou até sete meses, com a desculpa de que enviaria por transferência bancária para sua família no Peru (DUTRA, 2012).

Ou seja, o viver entre dois mundos constitui elemento próprio e característico das pessoas em mobilidade, já que só existe imigração para um determinado lugar na medida em que se tenha havido emigração de outro; a presença na sociedade de destino pressupõe a ausência na sociedade de origem. Assim é que Sayad (2000, p. 20) explica que isso constitui um dos paradoxos da imigração: “o imigrante está aqui e lá, está presente e ausente ou, invertendo os termos, não está aqui nem está lá, nem presente, nem ausente".

Outro trabalho, de Alessandro da Silva e Lorraine Souza (2015), sobre mulheres migrantes bolivianas em São Paulo, demonstrou através das entrevistas que em todas elas, tanto as que haviam deixado famílias como as que vieram solteiras, havia o desejo de retornar ao seu país de origem quando tivessem condições de viver bem na Bolívia. Sayad (2000) traz excelente reflexão sobre isso ao explicar que o retorno está intrinsecamente ligado ao fenômeno da migração, em função da presença naturalmente provisória do imigrante, sendo lembrado o tempo todo que ele não é daquele lugar, aquela não é sua terra.

No caso das mulheres migrantes, a situação é ainda mais agravada, pois precisam conviver com o fato do abandono familiar, o que é altamente condenável para toda mulher. A vida da imigrante experimenta o tempo todo "a ausência objetivamente culpável", fazendo-a lembrar de sua dupla falta e do vazio deixado com sua imigração (SAYAD, 2000, p. 18). Um caso apresentado em uma pesquisa de Arriagada e Moreno (2011) com imigrantes peruanas no Chile revelou como o fato de deixarem seus filhos no Peru lhes causava grandes conflitos emocionais, situação que se agravava ainda mais com os discursos alheios, como dos professores das crianças, que indicavam que essas haviam sido abandonadas.

Fatores esses que demandam especial atenção por parte do Estado, já sendo amplamente discutida a necessidade de facilitação e desburocratização para o envio de remessas de dinheiro por parte dos(as) migrantes, como forma de garantir o próprio projeto migratório desses sujeitos. Outra discussão que também é fundamental nesse ponto é sobre o direito à reunião familiar e a partir daí toda a importância de discutir sobre o papel estatal em termos de acolhimento, integração e acesso a direitos básicos dos filhos e filhas das migrantes.

Outro ponto fundamental no que tange à vulnerabilidade dessas mulheres é com relação à documentação e condição migratória, consideradas como um dos principais motivos que levam à exploração na relação de trabalho ou ao desemprego. Conforme explica Dutra (2013b, p. 185), "migrar tendo toda a documentação regularizada no país de destino não é algo corrente para mulheres com escassos recursos materiais e pouca qualificação formal". O estudo de Dutra (2013b, p. 186) mostra que das 20 paraguaias entrevistadas, 15 delas estavam em situação irregular no Brasil, "apesar de se tratar de um cenário de migração entre países do Mercosul, espaço onde atualmente existe o direito a migrar de forma regular".

Além disso, o sistema de vistos demanda que os(as) imigrantes retornem frequentemente às instituições responsáveis para renovar seus documentos e autorizações, tendo que constantemente justificar perante o Estado sua presença no território, relembrando-o de sua condição de subordinação à vontade estatal e de sua provisoriedade, podendo inclusive levar a uma situação irregular ou até deportação (LUSSI; MARINUCI, 2007).

O status migratório é, certamente, um dos fatores que mais distanciam as mulheres migrantes das nacionais, constituindo o modelo de controle das migrações com base na desejabilidade do Estado. Assim, a 
falta de documentação torna essas migrantes ainda mais vulneráveis pelo receio de serem penalizadas por sua situação irregular, trazendo dificuldades para acessar as políticas públicas e determinados serviços ofertados pelo Estado, "obstaculizando as poucas brechas de acesso que, oficialmente, algumas pudessem vir a usufruir". (DUTRA, 2013b, p. 186). Ou seja, a falta de documentação gera a perda do "poder de defender a própria dignidade enquanto ser humano". (LUSSI; MARINUCI, 2007, p. 5).

Patrícia Villen (2013) explica como as demandas pelo trabalho das mulheres migrantes se dão juntamente com as políticas migratórias de restrição e controle, o que contribui para a precarização das condições de trabalho e de vida dos imigrantes, em especial das mulheres. O sistema migratório controlado e ditado pelo Estado restringe e dificulta a mobilidade produzindo assim a ilegalidade, ou seja, se reconhece a "violência política como elemento-chave da reorganização do mercado de trabalho". (VILLEN, 2013, p. 7).

A condição de mulher e migrante intensifica os processos de exploração, já que, em muitos casos, essas mulheres precisam submeter-se às condições que lhe foram impostas em razão da necessidade de sobrevivência. Como mostra Parella (2005), os serviços domésticos se regulam por contratos débeis, ou seja, frágeis, além de estarem acompanhados de todo imaginário servil, da desvalorização ideológica como trabalho, da incidência da informalidade e do fato de realizar-se no espaço do lar. Todos esses elementos apontam a facilidade com que essa atividade favorece a invisibilidade e a indefesa dos sujeitos que se ocupam dele, o que os submete a uma grande margem de discricionariedade para cometimento de abusos, situação ainda mais evidente no caso das migrantes irregulares.

Outro destaque que se faz na análise das múltiplas vulnerabilidades da mulher migrante é com relação ao mercado de trabalho e como o processo migratório afeta e influencia na vida profissional das migrantes. Para isso, o trabalho desenvolvido por Dutra (2013b) é muito relevante, pois compara quais as profissões exercidas pelas mulheres antes de deixarem seus países de origem e a profissão exercida no país de migração. Segundo a pesquisa, do total de migrantes entrevistadas, quase dobrou o número de mulheres que passaram a exercer trabalhos ligados à assistência, como o serviço doméstico, cuidado de crianças ou idosos. Enquanto nos países de origem eram $15,2 \%$ das mulheres encontravam-se nesse nicho laboral, ao estabelecerem nos países de destino passaram a somar 29,3\% das entrevistadas (DUTRA, 2013b).

Nesse sentido, Acosta González (2013, p. 48, tradução nossa) traz a ideia de "solo pegajoso" do trabalho doméstico, tendo em vista que mesmo com o desenvolvimento do projeto migratório, torna-se muito difícil sair do circuito do trabalho doméstico, convertendo-se em um confinamento para as mulheres migrantes nesse nicho laboral. No caso das entrevistadas por Délia Dutra (2013b), nenhuma relatou exercer alguma profissão que não naturalmente considerada como feminina e dessa forma desvalorizada, sendo possível afirmar que a segregação laboral é ainda mais presente no caso das mulheres migrantes.

Silva e Souza (2015) explicam nesse sentido que o sistema de concessão de vistos que se baseia na necessidade de comprovação de trabalhos formais é um elemento que coloca as mulheres em desvantagem já que elas têm ainda menos acesso a postos de trabalho formais do que os homens. Comparando com os dados do Ministério do Trabalho, a diferença entre as autorizações de trabalho concedidas a estrangeiros é gigante e demonstra como as mulheres apresentam maiores dificuldades que os homens em regularizar seu trabalho: no ano de 2015 foram concedidas 32.479 autorizações para homens contra 4.389 autorizações para mulheres (ARAÚJO et al., 2016).

Assim, além de sofrerem com a segregação laboral que se utiliza da condição como migrante para destinar essas mulheres a trabalhos de pouca valorização e informais, também se percebe que há muitas barreiras para melhoria das condições de trabalho ou mobilidade social das migrantes, já que não conseguem ter acesso à rede educacional.

Portanto, a migração não tem sido uma via de acesso a instituições formalmente estabelecidas e reconhecidas pelas sociedades de acolhida onde as migrantes pudessem se qualificar e, consequentemente melhorar, não só no trabalho como também em outros âmbitos da vida pessoal. (DUTRA, 2013b, p. 189).

Nesse mesmo sentido, a pesquisa trouxe dados sobre o nível de escolaridade das migrantes entrevistadas, sendo que $20 \%$ delas declararam possuir nível superior completo e $12 \%$ superior incompleto, levando ao questionamento sobre as possibilidades profissionais das mulheres em mobilidade (DUTRA, 2013b). O grande debate nesse assunto e que coloca em xeque outro elemento característico das mulheres migrantes é com relação à difículdade de validação de suas formações técnicas e acadêmicas nos países em que se encontram, condicionando a possibilidade de exercício profissional em sua área de formação.

Handerson e Joseph (2015) realizaram uma pesquisa comparando a presença de imigrantes haitianas no Brasil e na França, tendo revelado exatamente essas realidades. Nas entrevistas com as haitianas no Brasil, elas declararam intenso sentimento de decepção com a migração, já que ambas tinham qualificação, mas que ao chegar 
ao Brasil a única oferta de emprego para elas era no setor doméstico. Os autores relataram que as experiências descritas pelas imigrantes passam pelas dificuldades de reconhecer seus diplomas estrangeiros, tendo que aceitar trabalhos não desejados, revelando a violência de um processo ainda marcado pelo racismo e xenofobia.

A exploração da mão de obra migrante se dá justamente pela impossibilidade de fazer valer direitos dentro do espaço público, como é o caso da validação de diplomas ou acesso à educação. A mão de obra migrante está no sistema capitalista para ser explorada conforme as demandas do mercado, sempre condicionando esses homens e mulheres àqueles cargos não desejados pelos nacionais; cuja qualificação não é necessária; cujas condições são precárias e em que prevalece a informalidade.

Daí a importância de considerar a necessidade de atuação estatal em processos que interrompam esse ciclo de dominação, através da facilitação do reconhecimento e validação de diplomas para garantir o acesso dessas mulheres ao mercado de trabalho em condições de igualdade e de políticas públicas para educação e formação das migrantes, de modo a possibilitar melhores condições de trabalho.

Outro ponto fundamental é com relação às condições de trabalho em que se encontram essas mulheres, situação que se agrava muito em razão de estar em um processo de mobilidade, ou seja, sujeito ao controle de permanência pelo Estado, preconceito e xenofobia, falta de vínculos e a quem recorrer, dentre outros. É o que mostra claramente o caso das migrantes domésticas peruanas em Brasília, já que todas relataram já ter vivido no próprio local de trabalho, sendo submetidas a longas jornadas de trabalho e com dias de folga eventualmente, além de sofrerem "uma situação de forte isolamento físico e psíquico". (DUTRA, 2012, p. 65).

Essa particularidade de muitas delas morar no mesmo local de trabalho, dá uma especificidade a nossas reflexões sobre a produção do espaço das migrantes. Isto porque, quando a trabalhadora doméstica mora no mesmo local de trabalho se produz geralmente uma relação empregador-empregada ambígua, dando como resultado, por exemplo, jornadas de trabalho de em média 16 horas, com intervalos muito breves para as refeições. Como já foi apontado, o direito de trabalhar oito horas diárias, assim como seu tempo de lazer, desaparece pelo fato da migrante morar no mesmo local de trabalho e não ter família a quem visitar ou dar atenção. (DUTRA, 2012, p. 70).

Parella (2005) demonstra também que as relações de dominação e exploração no serviço doméstico acabam por dar-se a partir de práticas autoritárias e que podem se revelar através de todo tipo de abuso, inclusive físicos. Nesse sentido, um caso apresentado por Dutra (2012) conta que uma das suas entrevistadas afirmou que nesse tipo de trabalho - o doméstico - se passa por muita humilhação e relata que não deseja que suas filhas também precisem trabalhar em casas de famílias que, segundo ela é um trabalho que causa muito sofrimento. No relato dessa entrevistada, ela conta que em todas as casas que trabalhou se preocupava muito em trancar bem a porta para dormir, pois tinha muito medo de sofrer abusos por parte dos patrões.

O caso de outra entrevistada é ainda mais grave, que migrou do Peru por oferta da própria família em que trabalhava lá, dizendo que poderia ir ao Brasil trabalhar na casa de uma parente. Ao chegar ao Brasil se hospedou com essa conhecida que a proibia de sair aos finais de semana e ainda exigia que ela trabalhasse no período da noite em troca do direito à moradia, quando retornava de outras casas onde trabalhava (DUTRA, 2012). Muitas situações de grave violação como essa dificilmente vem à tona, pois justamente o espaço privado do lar acoberta tais abusos e dificulta ainda mais o acesso aos direitos.

A socióloga [Chiaretti] chama atenção ao fato de que essa posição 'fechada nas paredes domésticas' foi 'atribuída à força de trabalho feminina pelo mercado mundial' e, para as imigrantes, significa um trabalho muito exposto ao arbítrio do empregador (pela total dependência do emprego para poder se manter no país de destino e ajudar a família no país de origem), com cargas intensivas de dispêndio de energia física e emocional, com 'tempo totalizante' de trabalho (tendo em vista que muitas vezes moram na casa do empregador e não há separação das horas de repouso daquelas de trabalho), com o peso de ter que cuidar de duas famílias, a do próprio emprego, bem como à distância, a de origem. (VILLEN, 2013, p. 5).

A problemática dos abusos sofridos pelas migrantes na relação de trabalho traz o questionamento sobre a possibilidade de acesso aos mecanismos institucionais que possam assim garantir direitos que coíbam abusos cometidos e reparem danos eventualmente sofridos. Sabe-se que a dificuldade de acesso a serviços públicos e à justiça é uma grande barreira na vida das migrantes, tanto pela falta de informação, barreiras linguísticas, despreparo dos agentes públicos responsáveis pelo atendimento, como inexistência de políticas específicas e/ou adequadas.

Traz-se novamente a realidade identificada por Silva e Souza (2015) com as migrantes bolivianas. No caso delas todas eram trabalhadoras nas oficinas de costura, sendo que as jornadas de trabalho variavam entre 64 e 79 horas semanais, e além do serviço de costura, algumas relatavam que também precisavam 
ajudar a cozinhar e a limpar o ambiente de trabalho que se dividia com o próprio lar. No contexto desta pesquisa puderam-se identificar também outros elementos que marcam a trajetória das mulheres migrantes. Diversos dos relatos apresentados mostraram as dificuldades das migrantes com o idioma, fator crucial para perpetuar seu isolamento e dificuldades em se relacionar com outras pessoas. O idioma também foi um problema apontado para que elas não buscassem os serviços públicos pelo medo de não serem compreendidas (SILVA; SOUZA, 2015).

Nas palavras de uma das imigrantes, ela diz que ainda não havia conversado com nenhum(a) brasileiros mesmo depois de sete meses residindo no país, revelando um elevado grau de isolamento. Outra migrante relatou que aqui no Brasil sentia ser de "ningun lugar", pois não conhecia ninguém e aos domingos ia a uma praça onde muitos bolivianos(as) se reuniam para "encontrar personas iguales a mi". (SILVA; SOUZA, 2015, p. 100). Outro fator determinante para seu isolamento era em função do sentimento de insegurança, já que tinham a percepção de São Paulo como uma cidade muito perigosa e também algumas revelaram ter medo da polícia, pois já haviam presenciado abordagens policiais a outros imigrantes (SILVA; SOUZA, 2015).

Todas as entrevistadas estavam indocumentadas no Brasil e os relatos mostraram que elas pouco interagem com a cidade e com as pessoas, sendo que as barreiras linguísticas, o trabalho, as mudanças culturais, a situação migratória e a insegurança não permitiam tempo livre (SILVA; SOUZA, 2015). No caso das trabalhadoras domésticas peruanas em Brasília, Dutra (2012) também destaca o intenso isolamento que sentem essas migrantes. "O espaço cotidiano em que vivem e trabalham é um espaço muito restrito, de confinamento, onde só se interage com integrantes da casa, e a comunicação com o 'fora' não é fluída, até muito dificultosa para algumas." (DUTRA, 2012, p. 166).

Assim, nota-se como o "paradoxo da liberdade de ir e vir e a produção de barreiras sociais, políticas e subjetivas geram as condições da opressão, da violência e no isolamento de imigrantes que não contam com papéis que lhes permitam existir para o Estado". (SILVA; SOUZA, 2015, p. 105-106). Essas realidades, de segregação laboral, trabalho excessivo e dificuldade de acesso a direitos só demonstram como a falta de reconhecimento político por parte de um Estado acaba por fazer com que uns sejam mais humanos do que outros (SILVA; SOUZA, 2015).

Percebe-se como a trajetória da mulher, migrante e doméstica é marcada por uma série de fatores de vulnerabilidade: barreiras linguísticas, isolamento, distância e afastamento da família, xenofobia, além de relações de trabalho precárias e informais. Constata-se assim que a migração feminina atual está intimamente ligada com a marca sexual da precarização do trabalho "e se insere na discussão do entendimento de como a condição da mulher imigrante se reflete nas três formas de canônicas de manifestação das relações de sexo exploração, dominação e opressão". (VILLEN, 2013, p. 20).

A partir de todas essas informações se conclui que não é ocasional a presença de mulheres migrantes em determinados nichos laborais, sendo que os fatores históricos de dominação feminina, somados ao sistema do espaço-tempo das migrações econômicas internacionais, produzem um sistema de exploração dessas mulheres, invisibilizando suas necessidades e especificidades.

\section{Considerações finais}

Seguiremos trabajando para construir puentes entre los pueblos, que nos permitan derribar los muros de la exclusión y la explotación. Carta de Santa Cruz, julio del 2015 (CARTA..., 2015).

Inerentes ao desenvolvimento do modo de produção capitalista em nível global estão suas próprias contradições, que se revelam tanto no plano material como simbólico, produzindo processos de desigualdade e exploração ao redor do mundo, em especial de mulheres e daquelas que migram, como estudado ao longo deste trabalho. Assim, o problema da presente pesquisa foi no sentido de compreender que elementos caracterizam as múltiplas vulnerabilidades das mulheres migrantes domésticas no país e consequentemente os desafios para uma política migratória brasileira atenta a esses processos de exploração e produção de desigualdades.

As migrações internacionais, como processo histórico, também se inserem na lógica do desenvolvimento capitalista e no caso das mulheres, essa análise contribuiu para compreender como se opera a segregação laboral e as relações de trabalho precarizadas. Assim como no advento do modo de produção capitalista a mão de obra infantil e de mulheres das classes mais baixas foi fundamental e necessária para maximização de lucros, hoje também a mão de obra migrante é útil à reprodução capitalista pela ampla exploração que a condição migratória proporciona. 
Assim, uma das principais conclusões foi no sentido de compreender como a realidade identificada nas vivências e experiência das mulheres migrantes domésticas no país não se dá de forma ocasional, mas está intrinsecamente ligada ao espaço-tempo das migrações internacionais contemporâneas, pela condição de migrante no modelo Estado-Nação e como o modo de produção capitalista e o patriarcado operam juntos no desenvolvimento dos processos de exploração dessas mulheres.

Em um segundo momento, pôde-se então identificar as múltiplas vulnerabilidades da realidade das migrantes domésticas no país, quais sejam: a) a presença provisória que a migração gera pela sua dupla presença ou dupla ausência nos países de destino e origem pelo afastamento da família e dos filhos, que gera maiores preconceitos para as mulheres migrantes na medida em que abandonam ou negam sua condição natural como mães para buscar melhores oportunidades em outros países. Preconceito esse carregado de desconhecimento e contradição, visto que o projeto migratório justamente é marcado pela dor da distância e muitas vezes têm como motivação justamente a possibilidade de dar melhores oportunidades aos filhos que ficaram no país de origem; b) a situação legal e a produção da clandestinidade em que viviam muitas mulheres entrevistadas que nega totalmente sua possibilidade de existirem como sujeitos políticos na sociedade, elemento que aprofunda ainda mais seu isolamento, possibilidade de acesso a direitos e políticas públicas e, principalmente, os abusos na relação de trabalho dentro do espaço doméstico do lar; e, por fim, c) a segregação laboral, imobilidade profissional e as discriminações étnico-raciais, elementos diretamente associados às construções de gênero e raça.

A partir dessas constatações é possível compreender como a política migratória brasileira acaba por ampliar e intensificar a realidade de segregação laboral, imobilidade profissional e discriminações étnico-raciais identificadas no desenvolver da segunda seção. O controle por parte do Estado que coloca a migração laboral a partir dos critérios de desejabilidade exclui a possibilidade de ingresso e permanência de todos(as) aqueles(as) que não são considerados(as) qualificados(as) para os padrões de desenvolvimento do país, ou seja, trata a migração a partir da sua possibilidade de trazer benefícios para a Nação. No caso das mulheres, essa lógica é ainda mais violenta, já que elas historicamente estão concentradas em nichos laborais pouco valorizados e naturalmente femininos, o que revelou o caráter não só classista, mas também sexista da política migratória de vistos para o trabalho.

Assim, entende-se que o controle da migração está para o modelo capitalista como forma de ampliar a exploração do trabalho de migrantes, visto que a condição da migração, por meio da atual política migratória brasileira (dificuldade de obtenção documentos, acesso a direitos, de comunicação, falta de referências e distância da família), as sujeita a relações de trabalho mais suscetíveis a abusos,

[...] o grande desafio é retirar a realidade dessas mulheres da invisibilidade, já que tanto o fato de serem mulheres, migrantes e domésticas se somam ao máximo para esconder dentro do espaço privado as relações de exploração que se expressam em termos de gênero, raça $\mathrm{e}$ classe. ao isolamento e à discriminação.

Mesmo com os avanços da Nova Lei de Migrações, cujo conteúdo se propõe a ser uma lei de direitos, ainda reproduz alguns elementos do paradigma do Estatuto do Estrangeiro ao privilegiar a migração qualificada em seu sistema de vistos e não prever a possibilidade de regularização migratória já dentro do território nacional, negando a possibilidade de documentar a migração de tantas pessoas que vêm em busca de trabalho no país. No caso estudado, o grande desafio é retirar a realidade dessas mulheres da invisibilidade, já que tanto o fato de serem mulheres, migrantes e domésticas se somam ao máximo para esconder dentro do espaço privado as relações de exploração que se expressam em termos de gênero, raça e classe.

\section{Referências}

ACOSTA GONZÁLEZ, E. Mujeres migrantes cuidadoras en flujos migratorios sur-sur y sur-norte: expectativas, experiencias y valoraciones. Polis, Santiago, v. 12, n. 35, p. 35-62, ago. 2013. Disponível em: <http://www.scielo.cl/ scielo.php?script=sci_arttext\&pid=S0718-65682013000200003\&lng=es\&nrm=iso $>$. Acesso em: 01 jul. 2017.

ARAÚJO, D. et al. Autorizações de Trabalho - Dados da Coordenação Geral de Imigração (CGIG) do Ministério do Trabalho. In: CAVALCANTI, L.; OLIVEIRA, A. T. de; ARAÚJO, D. (Org.). A inserção dos imigrantes no mercado de trabalho brasileiro. Relatório 
Anual 2016. Brasília, DF: OBMigra, 2016. p. 18-33. Disponível em: <https://laemiceppac.files.wordpress.com/2017/12/ relatoriocompleto_v8_0512_pagespelhada_comcapa-1.pdf $>$. Acesso em: 01 jul. 2017.

ARRIAGADA, I.; MORENO, M. La constitución de cadenas globales de cuidado y las condiciones laborales de las trabajadoras peruanas en Chile. In: STEFONI, C. (Ed.). Mujeres inmigrantes en Chile: ¿Mano de obra o trabajadoras con derechos? Santiago de Chile: Universidad Alberto Hurtado, 2011. p. 149-192.

BERTOLDO, J. Migração com rosto feminino: múltiplas vulnerabilidades, trabalho doméstico e desafios de políticas e direitos. 2017. 89 f. Trabalho de Conclusão de Curso (Graduação em Direito)-Universidade Federal de Santa Maria, Santa Maria, 2017.

CARTA de Santa Cruz de La Sierra. Segundo Encuentro Mundial de los Movimientos Populares, 10 jul. 2015. Disponível em: <http:/ /movimientospopulares.org/sale-la-carta-de-santa-cruz/>. Acesso em: 09 mar. 2018.

COMITÊ PARA ELIMINAÇÃO DA DISCRIMINAÇÃO CONTRA AS MULHERES. Recomendación general $n^{\circ} 26$ sobre las trabajadoras migratorias. enero 2005. Disponível em: <http://www.acnur.org/t3/fileadmin/Documentos/BDL/2012/8337.pdf?view=1>. Acesso em: 09 mar. 2018.

DUTRA, D. Mulheres do sul também migram para o sul, paraguaias no Brasil. Anuario Americanista Europeo, Helsinki, n. 11, p. 93108, 2013a. Disponível em: <http://repositorio.unb.br/bitstream/10482/22012/1/ARTIGO_MulheresSul\%20também\%28migram.pdf>. Acesso em: 09 mar. 2018.

Mulheres migrantes peruanas em Brasilia: o trabalho doméstico e a produção do espaço na cidade. 2012. $236 \mathrm{f}$. Tese (Doutorado em Sociologia)-Universidade de Brasília, Brasília, DF, 2012. Disponível em: <http://repositorio.unb.br/handle/10482/ 11418>. Acesso em: 05 jun. 2017.

. Mulheres, migrantes, trabalhadoras: a segregação no mercado de trabalho. Revista Interdisciplinar da Mobilidade Humana, Brasília, DF, v. 21, n. 40, p. 177-193, jun. 2013b. Disponível em: <http://www.scielo.br/pdf/remhu/v21n40/11.pdf>. Acesso em: 05 jun. 2017.

HANDERSON, J.; JOSEPH, R.-M. As relações de gênero, de classe e de raça: mulheres migrantes haitianas na França e no Brasil. Revista de Estudos e Pesquisas sobre as Américas, Brasília, DF, v. 9, n. 2, p. 1-33, 2015. Disponível em: <http://periodicos.unb.br/ index.php/repam/article/view/17266>. Acesso em: 04 jun. 2017.

LISBOA, T. K. Fluxos migratórios de mulheres para o trabalho reprodutivo: a globalização da assistência. Revista Estudos Feministas, Florianópolis, v. 15, n. 3, p. 805-821, set./dez. 2007. Disponível em: <https://periodicos.ufsc.br/index.php/ref/article/view/S0104026X2007000300017>. Acesso em: 17 mar. 2017.

LUSSI, C. Conflitos e vulnerabilidades no processo migratório. Centro Scalabriniano de Estudos Migratórios, 2009. Disponível em: $<$ http://www.csem.org.br/2009/conflitos_e_vulnerabilidades_no_processo_migratorio.pdf $>$. Acesso em: 05 jun. 2017.

.; MARINUCI, R. Vulnerabilidade social em contexto migratório. Centro Scalabriniano de Estudos Migratórios, 2007. Disponível em: <http://www.csem.org.br/pdfs/vulnerabilidades_dos_migrantes.pdf >. Acesso em: 15 jun. 2017.

MAGLIANO, M. J. Mujeres, migración y roles de género. El caso de la migración boliviana hacia Argentina. In: JORNADAS INTERESCUELAS/DEPARTAMENTOS DE HISTORIA, 11., 2007, San Miguel de Tucumán. Anais... San Miguel de Tucumán: Universidad de Tucumán, 2007. Disponível em: <http://cdsa.aacademica.org/000-108/162>. Acesso em: 01 jul. 2017.

ORGANIZAÇÃO DAS NAÇÕES UNIDAS. Trends in international migration, 2015. POPFACTS, n. 2015/4. [New York]: United Nations, 2015. Disponível em: <http://www.un.org/en/development/desa/population/migration/publications/populationfacts/docs/ MigrationPopFacts20154.pdf>. Acesso em: 11 jun. 2017.

ORGANIZAÇÃO INTERNACIONAL DO TRABALHO. ILO Global estimates of migrant workers and migrant domestic workers: results and methodology. Geneva: ILO, 2015. Disponível em: <http:/www.ilo.org/wcmsp5/groups/public/@dgreports/@dcomm/ documents/publication/wcms_436343.pdf >. Acesso em: 15 maio 2017.

PARELLA, S. Segregación laboral y "vulnerabilidad social” de la mujer inmigrante a partir de la interacción entre clase social, género y etnia. In: FLAQUER, L.; SOLÉ, C. (Ed.). El uso de las políticas sociales por las mujeres inmigrantes. Madrid: Instituto de la Mujer (Ministerio de Trabajo y Asuntos Sociales), 2005. p. 95-138. Disponível em: <http://www.unav.edu/matrimonioyfamilia/observatorio/ indexbase.php?cmd=search4\&id=20646>. Acesso em: 05 jun. 2017.

REDIN, G. Direito de imigrar: direitos humanos e espaço público. Florianópolis: Conceito Editorial, 2013.

SAYAD, A. O retorno: elemento constitutivo da condição do imigrante. Travessia, São Paulo, ano 13, n. esp., jan. 2000.

SILVA, A. S.; SOUZA, L. L. Trabalho, Lazer e relações de Gênero na Ótica de Mulheres Imigrantes. Revista Electrónica de Psicología Política, San Luis, ano 13, n. 35. p. 72-109, dic. 2015. Disponível em: <http://www.psicopol.unsl.edu.ar/2015-Diciembre-05.pdf $>$. Acesso em: 11 jun. 2017.

TAYAH, M.-J. Decent work for migrant domestic workers: moving the agenda forward. Geneva: ILO, 2016. Disponível em: <http:// www.ilo.org/global/topics/labour-migration/publications/WCMS_535596/lang—en/index.htm>. Acesso em: 12 maio 2017.

VILLEN, P. Mulheres na imigração qualificada e de baixa qualificação: uma modalidade da divisão sexual do trabalho no Brasil. In: CONGRESSO LATINO-AMERICANO DE ESTUdOS DO TRABALHO, 7., 2013, São Paulo. Anais... São Paulo: ALAST, 2013. Disponível em: $<$ http://docplayer.com.br/16411893-Mulheres-na-imigracao-qualificada-e-de-baixa-qualificacao-uma-modalidade-dadivisao-sexual-do-trabalho-no-brasil.html\#show_full_text>. Acesso em: 04 jun. 2017.

YEATES, N. Global Care Chains. International Feminist Journal of Politics, v. 6, n. 3, p. 369-391, 2004. Disponível em: <http:// www.tandfonline.com/doi/abs/10.1080/1461674042000235573>. Acesso em: 02 jul. 2017. 


\section{Nota}

1 Esse artigo apresentou como base apesquisa realizada para a monografia de conclusãode curso Migração com rosto feminino: múltiplas vulnerabilidades, trabalho doméstico e desafios de politicas e direitos, defendida e aprovada em julho de 2017, no Curso de Graduação em Direito da UniversidadeFederal de Santa Maria, sob a orientação da Prof. ${ }^{a} r^{a}{ }^{a}$ Giuliana Redin (UFSM) (BERTOLDO, 2017).

\section{Jaqueline Bertoldo}

bertoldojaque@gmail.com

Bacharel em Direito pela Universidade Federal de Santa Maria (UFSM)

Mestranda em Direito pela Universidade Federal de Santa Maria (UFSM)

\section{UFSM}

Av. Roraima, $n^{\circ} 1000$, Cidade Universitária - Bairro Camobi

Santa Maria - Rio Grande do Sul - Brasil

CEP: 97.105-900

Agência financiadora

Não se aplica.

Contribuições dos autores

Não se aplica.

\section{Consentimento para publicação}

Não se aplica.

\section{Conflito de interesses}

Não há conflito de interesses.

Aprovação por Comitê de Ética e consentimento para participação

Não se aplica. 